DOI: 10.12731/2658-6649-2019-11-4-118-126

УДК 616.71-002.4

\title{
ВЛИЯНИЕ МЕЛАКСЕНА \\ НА ПОКАЗАТЕЛИ ПЕРЕКИСНОГО ОКИСЛЕНИЯ ЛИПИДОВ И АНТИОКСИДАНТНОЙ ЗАЩИТЫ В ЭКСПЕРИМЕНТЕ ПРИ ХРОНИЧЕСКОМ ОДОНТОГЕННОМ ОСТЕОМИЕЛИТЕ ЧЕЛЮСТЕЙ
}

\section{Тобоев Г.В., Алиев К.И.}

Исследование проведено на 50 крысах - самцуах линии Вистар, массой 200-300 грамм. Во всех группах животных, кроме фоновой, создавалась модель одонтогенного остеомиелита нижней челюсти. В контрольной группе проводилось стандартное лечение, предлагаемое при данной патологии. Опытной группе крыс помимо стандартной терапии вводился препарат «Мелаксен». На 40й, 45й и 50й сутки эксперимента определялись показатели перекисного окисления липидов (ПОЛ) и антиоксидантной зашчиты для выяснения стадии развития воспаления и сформированности защиттных реакций организма. Показано, что стандартная терапия одонтогенного остеомиелита способствует некоторому снижению активности ферментов оксидативного стресса. Использование препарата «Мелаксен» приводило к достоверно более выраженному уменьшению показателей ПОЛ и активации антиоксидантной защиты.

Ключевые слова: одонтогенный остеомиелит; перекисное окисление липидов; антиоксидантная защчита.

\section{EFFECTS OF MELAXEN ON THE INDICES OF LIPID PEROXIDATION AND ANTIOXIDANT DEFFENCE IN EXPERIMENT IN CHRONIC ODONTOGENIC OSTEOMYELITIS OF JAWS}

\section{Toboev G.V., Aliev K.I.}

The study was performed on 50 male Wistar rats, weighing 200-300 grams. A model of odontogenic mandibular osteomyelitis was created in all 
the animals, except the background group. In the control group, the standard treatment of this pathology was performed. In addition to the standard therapy, the experimental group of rats was injected with the drug Melaxen. On the 40rd, 45th, 50th, 55th days of the experiment, the indices of lipid peroxidation (LPO) and antioxidant protection were studied to determine the stage of inflammation development and the formation of protective reactions of the body. It has been shown that standard therapy of odontogenic osteomyelitis contributes to a certain decrease in the activity of oxidative stress enzymes and an increase in LPO. The use of the drug "Melaxen» led to a significantly more pronounced decrease in indicators of LPO and activation of antioxidant protection.

Keywords: odontogenic osteomyelitis; lipid peroxidation; antioxidant protection.

\section{Введение}

Лечение хронического остеомиелита - одна из наиболее сложных и актуальных проблем хирургической стоматологии, что связано с особенностями локализации остеомиелитических полостей, тяжестью течения патологического процесса, высокой склонностью к рецидивированию. Таким образом, поиск новых альтернативных методов лечения одонтогенных остеомиелитов, основанных на патогенезе заболевания - важная задача современной медицины $[1,7]$.

Известно, что основным патогенетическим механизмом развития любого патологического процесса является активация свободнорадикального окисления биомолекул [8]. Как свидетельствуют данные литературы, перекисное окисление липидов (ПОЛ) запускается и при остеомиелитах челюстей. Фактором, сдерживающим развитие окислительного стресса, является многокомпонентная многоуровневая антиоксидантная система организма, включающая супероксиддисмутазу, каталазу, глутатионпероксидазы, глутатион-редуктазу, глутатионтрансферазы, глюкозо-6-фосфатдегидрогеназу и др. Активация свободнорадикальных процессов ведет к развитию окислительного стресса - нарушению баланса между анти- и прооксидантными системами [2,6].

В настоящее время доказано [3], что гормон эпифиза мелатонин является мощным протектором, сдерживающим развитие воспалительных реакций. Выяснено, что мелатонин способен снижать выраженность процессов ПОЛ в клеточных структурах, уменьшать количество активных форм кислорода, защищать клеточные мембраны от их деструктивного 
действия, проникая через все биологические барьеры и активно участвуя в метаболизме свободных радикалов. Мелатонин также регулирует процессы клеточного и гуморального иммунитета. Установлено, при снижении иммунореактивности организма введение мелатонина приводит к стимуляции иммунных механизмов защиты организма [4].

В связи с описанными свойствами гормона эпифиза нами было сделано предположение, что включение препарата «Мелаксен»- синтетического аналога мелатонина - в стандартную схему лечения одонтогенного остеомиелита должно оказать протекторное воздействие при развитии патологического воспалительного процесса. В качестве параметров, характеризующих выраженность развития остеомиелита, были выбраны показатели ПОЛ и антиоксидантной защиты.

Целью работы являлось изучение показателей ПОЛ и антиоксидантной защиты при хроническом одоногенном остеомиелите челюстей в эксперименте на крысах-самцах линии Вистар при проведении стандартного патогенетического лечения, а также при сочетании классической схемы терапии с использованием препарата «Мелаксен».

\section{Материал и методы исследования}

Работа проведена на 60 крысах-самцах линии Вистар, массой 200-300 грамм, разделенных на 4 экспериментальные группы:

1) интактные животные;

2) животные с хроническим одонтогенным остеомиелитом челюстей;

3) животные с хроническим одонтогенным остеомиелитом челюстей, получавшие стандартное лечение;

4) животные с хроническим одонтогенным остеомиелитом челюстей, получавшие стандартное лечение в сочетании с препаратом «Мелаксен»;

Модель хронического одонтогенного остеомиелита челюстей создавалась путем удаления зуба и введения в лунку марлевой турунды, смоченной $20 \%$ спиртовым раствором нитрата серебра, и последующей фиксации ее в ране. Формирование хронического одонтогенного остеомиелита происходило на 30-40 сутки после оперативного вмешательства (что подтверждалось гистологической картиной).

В состав медикаментозной терапии в контрольной группе животных входили: цефазолин, диазолин, 5\% р-р аскорбиновой кислоты и $10 \%$ раствор глюконата кальция. Препарат Мелаксен (Unipharm, USA) вводили ежедневно внутрижелудочно в течение всего срока лечения. Дозировка 
лекарственных средств рассчитывалась в пересчете на массу тела животного с тем, чтобы добиться соответствия концентрации препарата в крови животных аналогичному показателю в крови взрослого человека.

Активность процессов перекисного окисления липидов исследовалась на 40-е, 45-е, и 50-е сутки эксперимента путем определения уровня малонового диальдегида в эритроцитах и гидроперекисей в плазме крови экспериментальных крыс. Функциональное состояние системы антиоксидантной защиты организма оценивали посредством определения активности каталазы в эритроцитах.

Концентрацию малонового диальдегида (МДА) в эритроцитах животных определяли спектрофотометрически в реакции с тиобарбитуровой кислотой. Концентрацию гидроперекисей в плазме крови изучали по ультрафиолетовому поглощению липидных экстрактов крови с помощью набора «ТБК-АГАТ (Биоконт)» на спектрофотометре. Активность каталазы в эритроцитах также исследовали спектрофотометрически по методу, основанному на определении скорости разложения перекиси водорода в единицу времени [5].

Результаты всех экспериментальных исследований были статистически обработаны с применением критерия «t» Стьюдента методом вариационного анализа, с помощью программы Statistica 6.0

\section{Результаты и обсуждение}

На 40-й день эксперимента у крыс со сформировавшимся хроническим одонтгенным остеомиелитом челюстей отмечалось выраженное изменение показателей активности ПОЛ и антиоксидантной защиты по сравнению с фоновыми значениями. Это и объяснимо, поскольку доказывает наличие воспалительного процесса.

Так, концентрация малонового диальдегида у крыс с хроническим одонтогенным остеомиелитом на 40 -е сутки от начала эксперимента оказалась практически вдвое выше фоновых значений $(\mathrm{p} \leq 0,001)$. При отсутствии лечения, патология прогрессировала и к 50-м суткам данный показатель значительно увеличился $(\mathrm{p} \leq 0,001)$. Стандартная терапия способствовала достоверному снижению концентрации малонового диальдегида относительно значений, полученных у нелеченных крыс $(\mathrm{p} \leq 0,001)$. Однако на 50-е сутки показатель оставался значительно выше фоновых цифр. Включение «Мелаксена» в схему лечения остеомиелита позволило добиться достоверного уменьшения содержания малонового диальдегида в эритроцитах крыс уже на 45 -е сутки $(\mathrm{p} \leq 0,01)$ от начала эксперимента и 
приблизиться к фоновым значениям данного показателя активности ПОЛ к 50-м суткам, (см. рисунок 1 ).

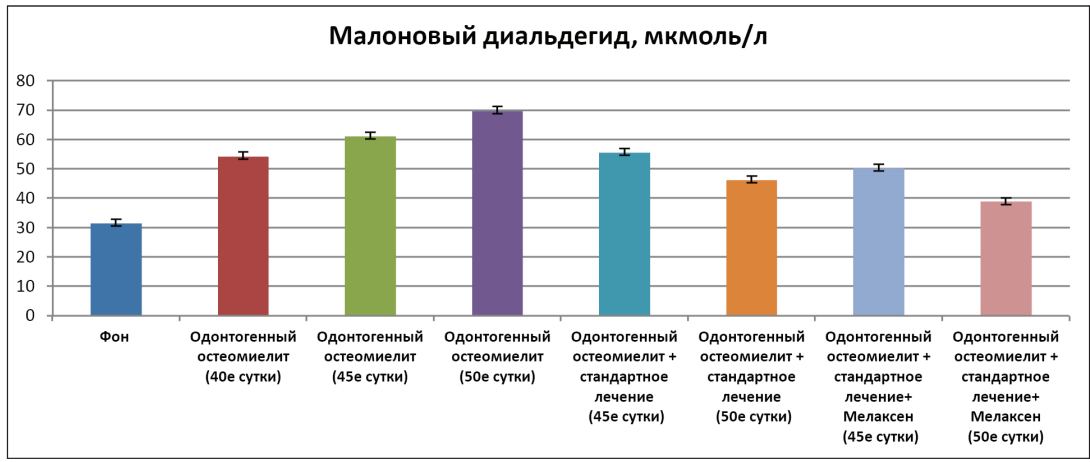

Pис. 1. Изменение концентрации малонового диальдегида в эритроцитах крыс с хроническим одонтогенным остеомиелитом челюстей

Содержание гидроперекисей в плазме крови животных с экспериментальной патологией на всех контрольных сроках достоверно превышало значения, полученные у интактных крыс $(\mathrm{p} \leq 0,001)$. В опытной группе, которой проводилась стандартная терапия одонтогенного остеомиелита, имело место снижение указанного показателя ПОЛ $(\mathrm{p} \leq 0,05)$ по сравнению с нелеченной группой, как на 45-е, так и на 50-е сутки. Применение «Мелаксена» ещё более выражено уменьшало содержание гидроперекисей в плазме крови животных $(\mathrm{p} \leq 0,001)$ и улучшала эффект классической схемы лечения $(\mathrm{p} \leq 0,05)$, (см. рисунок 2$)$.

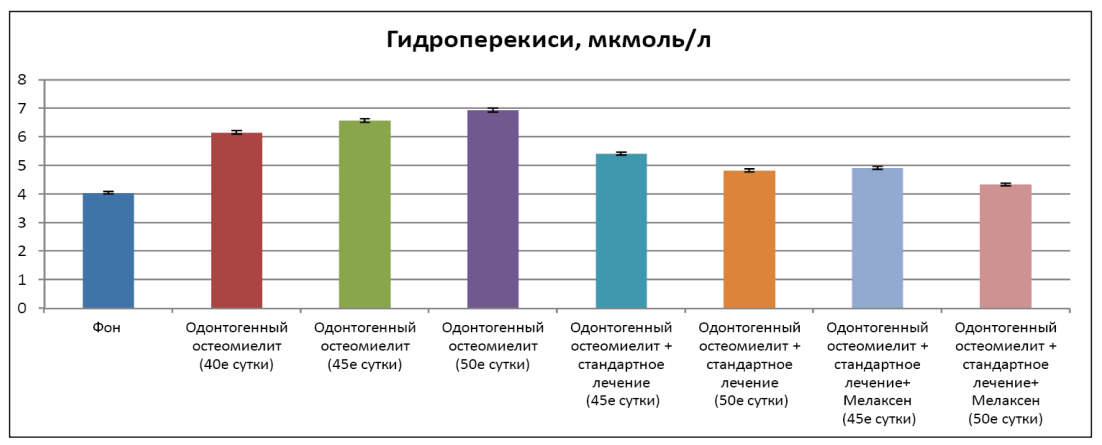

Рис. 2. Изменение концентрации гипоперекиси в плазме крови крыс с хроническим одонтогенным остеомиелитом челюстей 
Антиоксидантная защита также претерпела значительные изменения. Концентрация каталазы в условиях экспериментального одонтогенного остеомиелита челюстей прогрессивно снижалась $(\mathrm{p} \leq 0,001)$. Проведение стандартного лечения данной патологии приводило к частичному восстановлению антиоксидантной защиты к 50 -м суткам ( $\mathrm{p} \leq 0,05)$, а использование «Мелаксена» позволило достичь значений близких к фоновым $(\mathrm{p} \leq 0,05)$, (см. рисунок 3 ).

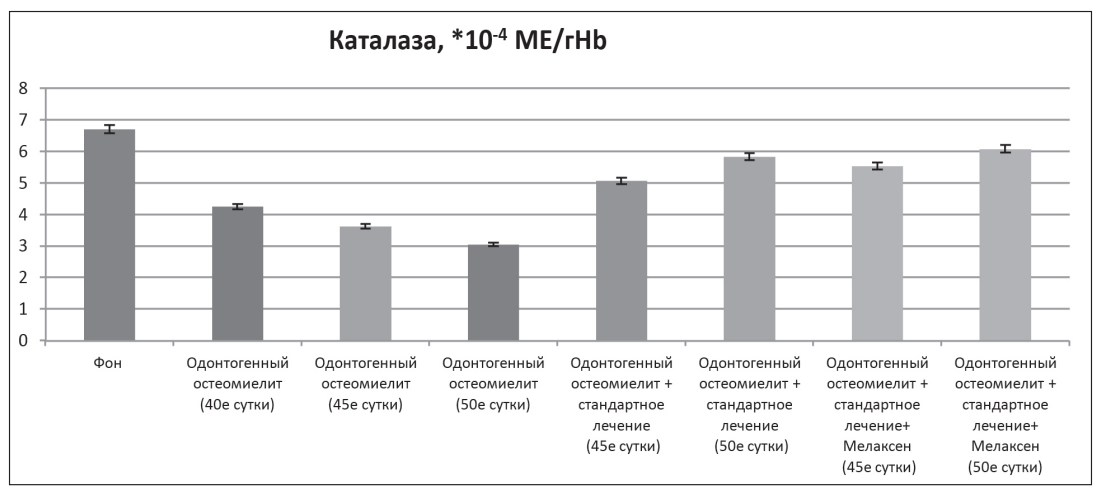

Рис. 3. Изменение концентрации каталазы в эритроцитах крыс с хроническим одонтогенным остеомиелитом челюстей

Таблица.

Изменения показателей ПОЛ и антиоксидантной защиты у крыс с хроническим одонтогенным остеомиелитом челюстей $(\mathrm{M} \pm \mathrm{m})$

\begin{tabular}{|c|c|c|c|c|c|c|c|}
\hline \multirow[t]{2}{*}{$\begin{array}{l}\text { № } \\
\text { п/II }\end{array}$} & \multirow[t]{2}{*}{$\begin{array}{c}\text { Экспериментальные } \\
\text { группы }\end{array}$} & \multicolumn{2}{|c|}{$\begin{array}{l}\text { Малоновый } \\
\text { диальдегид, } \\
\text { мкмоль/л }\end{array}$} & \multicolumn{2}{|c|}{$\begin{array}{l}\text { Гидропере- } \\
\text { киси, мк- } \\
\text { моль/л }\end{array}$} & \multicolumn{2}{|c|}{$\begin{array}{c}\text { Каталаза, } \\
\text { *10-4 ME/ } \\
\text { гНb }\end{array}$} \\
\hline & & $\mathbf{M} \pm \mathbf{m}$ & $\mathbf{p}$ & $\mathbf{M} \pm \mathbf{m}$ & $\mathbf{p}$ & $\mathbf{M} \pm \mathbf{m}$ & $\mathbf{p}$ \\
\hline 1 & Интактные животные (фон) & $31,49 \pm 1,26$ & & $4,04 \pm 0,19$ & & $6,71 \pm 0,18$ & \\
\hline 2 & $\begin{array}{l}\text { Животные с эксперимен- } \\
\text { тальным одонтогенным } \\
\text { остеомиелитом ( } 40 \text {-е сутки) }\end{array}$ & $\begin{array}{c}54,26 \pm \\
1,42\end{array}$ & *) & $6,15 \pm 0,20$ & $*)$ & $4,25 \pm 0,21$ & $*)$ \\
\hline 3 & $\begin{array}{l}\text { Животные с эксперимен- } \\
\text { тальным одонтогенным } \\
\text { остеомиелитом (45-е сутки) }\end{array}$ & $61,11 \pm 1,38$ & *) & $6,57 \pm 0,18$ & $*)$ & $3,62 \pm 0,19$ & $*)$ \\
\hline 4 & $\begin{array}{l}\text { Животные с эксперимен- } \\
\text { тальным одонтогенным } \\
\text { остеомиелитом ( } 50 \text {-е сутки) }\end{array}$ & $69,71 \pm 1,50$ & $*)$ & $6,94 \pm 0,20$ & $*)$ & $3,05 \pm 0,23$ & $*)$ \\
\hline
\end{tabular}


Окончание табл.

\begin{tabular}{|c|c|c|c|c|c|c|c|}
\hline 5 & $\begin{array}{l}\text { Животные с эксперименталь- } \\
\text { ным одонтогенным остеомие- } \\
\text { литом, получающие стандарт- } \\
\text { ное лечение (45-е сутки) }\end{array}$ & $55,63 \pm 1,33$ & \#) & $5,42 \pm 0,10$ & \# ) & $5,07 \pm 0,14$ & \#) \\
\hline 6 & $\begin{array}{l}\text { Животные с эксперимен- } \\
\text { тальным одонтогенным } \\
\text { остеомиелитом, получаю- } \\
\text { щие стандартное лечение } \\
\text { (50-е сутки) }\end{array}$ & $46,17 \pm 1,40$ & \#) & $4,82 \pm 0,17$ & \# ) & $5,83 \pm 0,13$ & \#) \\
\hline 7 & $\begin{array}{l}\text { Животные с эксперименталь- } \\
\text { ным одонтогенным остеоми- } \\
\text { елитом, получающие стан- } \\
\text { дартное лечение в сочетании } \\
\text { с Мелаксеном (45-е сутки) }\end{array}$ & $50,18 \pm 1,29$ & $\begin{array}{l}\#) \\
\S)\end{array}$ & $4,91 \pm 0,13$ & $\begin{array}{l}\#) \\
\S)\end{array}$ & $5,54 \pm 0,15$ & $\begin{array}{l}\# \text { ) } \\
\S)\end{array}$ \\
\hline 8 & $\begin{array}{l}\text { Животные с эксперимен- } \\
\text { тальным одонтогенным } \\
\text { остеомиелитом, получаю- } \\
\text { щие стандартное лечение в } \\
\text { сочетании с Мелаксеном } \\
\text { (50-е сутки) }\end{array}$ & $\begin{array}{c}38,86 \pm \\
1,31\end{array}$ & $\begin{array}{l}\#) \\
\S)\end{array}$ & $\begin{array}{c}4,33 \pm \\
0,11\end{array}$ & $\begin{array}{l}\#) \\
\S)\end{array}$ & $\begin{array}{c}6,08 \pm \\
0,12\end{array}$ & $\begin{array}{l}\# \text { ) } \\
\S)\end{array}$ \\
\hline
\end{tabular}

Примечание:

- $\quad(*)$ - достоверное $(\mathrm{p} \leq 0,001)$ изменение по сравнению с фоном;

- $\quad$ (\#) - достоверное $(\mathrm{p} \leq 0,001)$ изменение относительно группы животных с нелеченным хроническим одонтогенным остеомиелитом челюстей;

- $\quad(\S)$ - достоверное $(\mathrm{p} \leq 0,05)$ изменение относительно группы животных со стандартной терапией хронического одонтогенного остеомиелита челюстей.

\section{Выводы}

Установлено, что препарат «Мелаксен» в сочетании со стандартной терапией хронического одонтогенного остеомиелита оказывает протекторное влияние на развитие патологического процесса в эксперименте, снижая активность ПОЛ и стимулируя антиоксидантную защиту организма.

\section{Список литературы}

1. Bali R.K. et al. A review of complications of odontogenic infections // Natl J Maxillofac Surg. 2015 Jul-Dec;6(2):136-43.

2. Julien Saint Amand M. et al. Chronic osteomyelitis of the mandible: A comparative study of 10 cases with primary chronic osteomyelitis and 12 cases with secondary chronic osteomyelitis // J Stomatol Oral Maxillofac Surg. 2017 Dec;118 (6): 342-348. 
3. Баллюзак М.Ф., Гриненко Т.Н., Кветная Т.В. Роль мелатонина в развитии метаболического синдрома // Клиническая медицина. 2009. №6. С. 26-31.

4. Кабанова А.А. Свободнорадикальное окисление при гнойновоспалительных процессах челюстно-лицевой области // Вестник Витебского государственного медицинского университета. 2013. Т. 12. №. 1.

5. Камышников В.С. Справочник по клинико-биохимической лабораторной диагностике. Мн.: Беларусь. 2000. Т. 2. С. 463.

6. Рекова Л.П., Сторожева М.В., Бакшеева В.А. Динамика показателей перекисного окисления липидов в зависимости от вида острого одонтогенного воспалительного процесса // Український стоматологічний альманах. 2013. № 1 .

7. Фомичев Е.В., Островский О.В., Кирпичников М.В. Эффективность лечения больных травматическим остеомиелитом нижней челюсти с помощью эфферентных методов // Волгоградский научно-медицинский журнал. 2010. №. 3 (27).

8. Хасанов А.И., Абдулаев Ш.Ю. Значение уровня продуктов перекисного окисления липидов для прогнозирования травматического остеомиелита нижней челюсти // Стоматология. 2002. Т. 2. С. 27-2.

\section{References}

1. Bali R.K. et al. A review of complications of odontogenic infections. Natl J Maxillofac Surg. 2015 Jul-Dec;6(2):136-43.

2. Julien Saint Amand M. et al. Chronic osteomyelitis of the mandible: A comparative study of 10 cases with primary chronic osteomyelitis and 12 cases with secondary chronic osteomyelitis. J Stomatol Oral Maxillofac Surg. 2017 Dec;118 (6): 342-348.

3. Ballyuzak M.F., Grinenko T.N., Kvetnaya T.V. Klinicheskaya meditsina. 2009. №6, pp. 26-31.

4. Kabanova A.A. Vestnik Vitebskogo gosudarstvennogo meditsinskogo universiteta. 2013. V. 12. №. 1.

5. Kamyshnikov V.S. Spravochnik po kliniko-biokhimicheskoy laboratornoy diagnostike [Handbook of clinical and biochemical laboratory diagnostics]. Mn.: Belarus'. 2000. V. 2. P. 463.

6. Rekova L.P., Storozheva M.V., Baksheeva V.A. Ukraïns'kiy stomatologichniy al'manakh. 2013. №. 1.

7. Fomichev E. V., Ostrovskiy O. V., Kirpichnikov M. V. Volgogradskiy nauchnomeditsinskiy zhurnal. 2010. №. 3 (27).

8. .Khasanov A. I., Abdulaev Sh. Yu. Stomatologiya. 2002. T. 2. S. $27-2$. 
ДАННЫЕ ОБ АВТОРАХ

Тобоев Г.В., Алиев К.И.

ФГБОУ ВО СОГМА Минздрава России

ул. Пушкинская, 40, г. Владикавказ, 362019, Российская Федерачия gtoboev@yandex.ru

\section{DATA ABOUT THE AUTHORS}

Toboev G.V., Aliev K.I.

North Ossetian State Medical Academy

40, Pushkinskaya Str., Vladikavkaz, 362019, Russian Federation

gtoboev@yandex.ru 